\title{
Space Launch System Ascent Aerothermal Environments Methodology
}

Christopher I. Morris

NASA Marshall Space Flight Center

Aerosciences Branch/EV33

January 6, 2015 


\section{Overview}

- Space Launch System (SLS) Overview

- SLS External Thermal Analysis Status and Plans

- Overall External Thermal Analysis Approach

- External Thermal Environments Processes and Codes

- Aerodynamic Heating

- CLVMIN

- Protuberance Heating

- Small Protuberance Methodology

- Plume Radiation Heating

- Base Convective Heating

- Plume-Induced Flow Separation Heating

- Plume Impingement Heating

- Summary and Status 


\section{Space Launch System (SLS)}

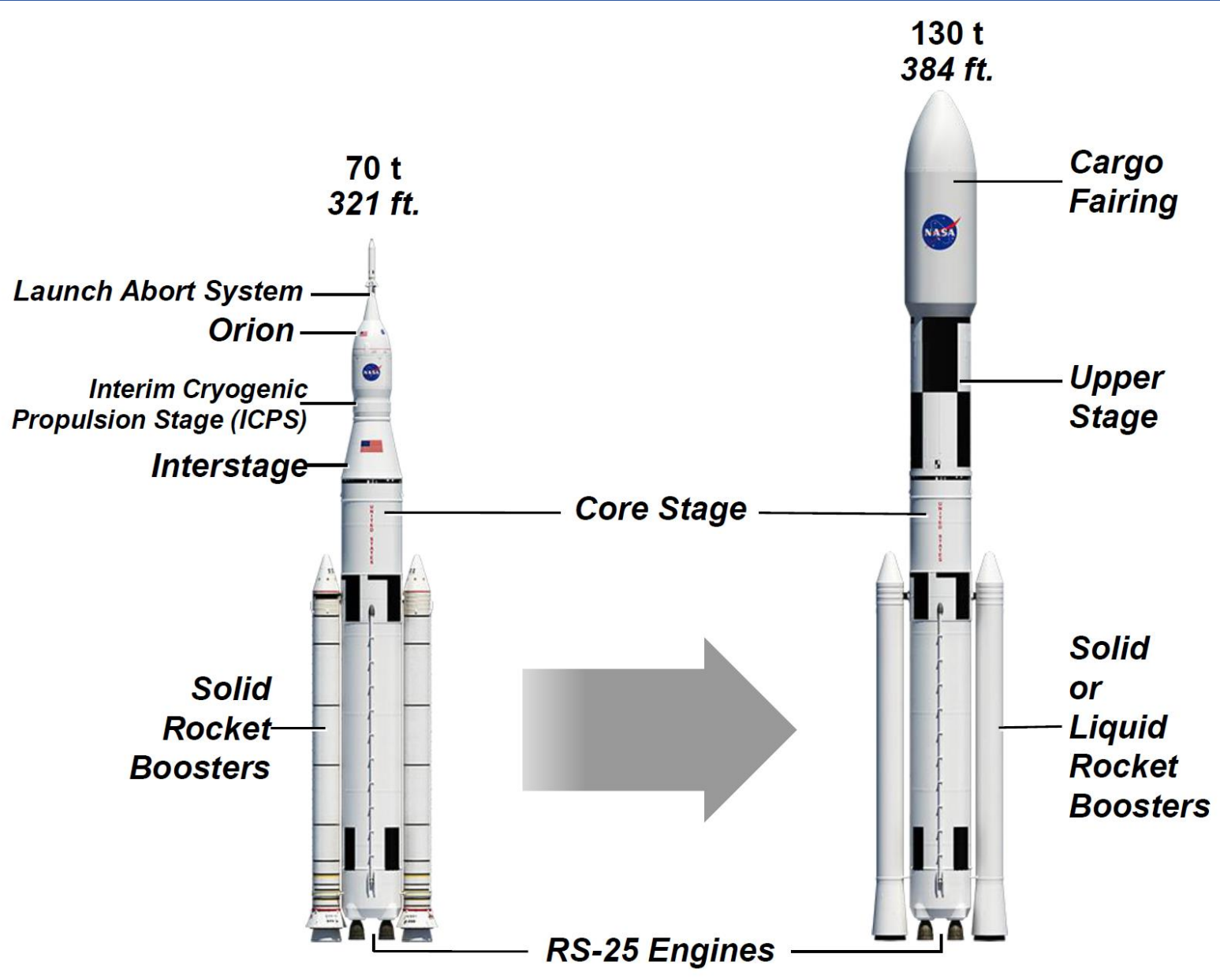

- SLS will enable human exploration beyond low Earth orbit (LEO)

- Block I vehicle will initially lift $\mathbf{7 0}$ metric tons (mT) to LEO, will evolve to $130 \mathrm{mT}$ to LEO (Block II) 


\section{Block I SLS Vehicle}

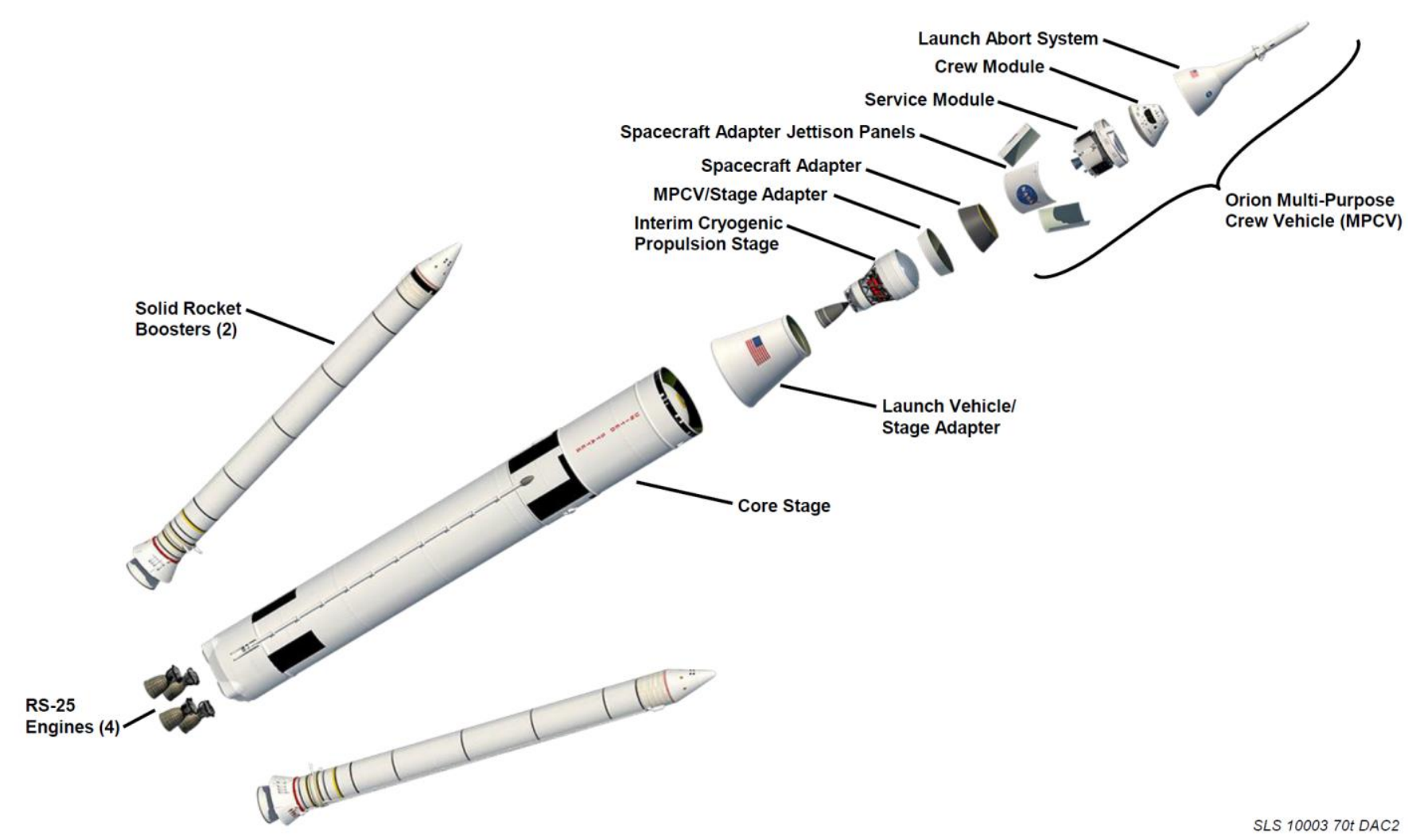

- Liquid $\mathrm{H}_{2} / \mathrm{O}_{2}$ Core Stage, supplying four RS-25 engines

- Five segment Solid Rocket Boosters

- Integrated Spacecraft and Payload Element (ISPE)

- Orion Multi-Purpose Crew Vehicle (MPCV) 


\section{SLS External Thermal Analysis Status and Plans}

- SLS Program passed Preliminary Design Review (PDR) in July, 2013

- Design Analysis Cycles (DAC) 1 and 2 were completed and informed the vehicle design before PDR

- Vehicle external thermal environments were generated for 2080 body point locations on the vehicle in DAC2

- Delivered as engineering data and also documented in official SLS program documentation

- SLS Program Critical Design Review (CDR) scheduled for May, 2015

- DAC3 and DAC3R were completed in the past year

- Vehicle external thermal environments were generated for 2737 body point locations on the vehicle in DAC3R

- Final revisions to official SLS program design documents are underway in preparation for the vehicle CDR 


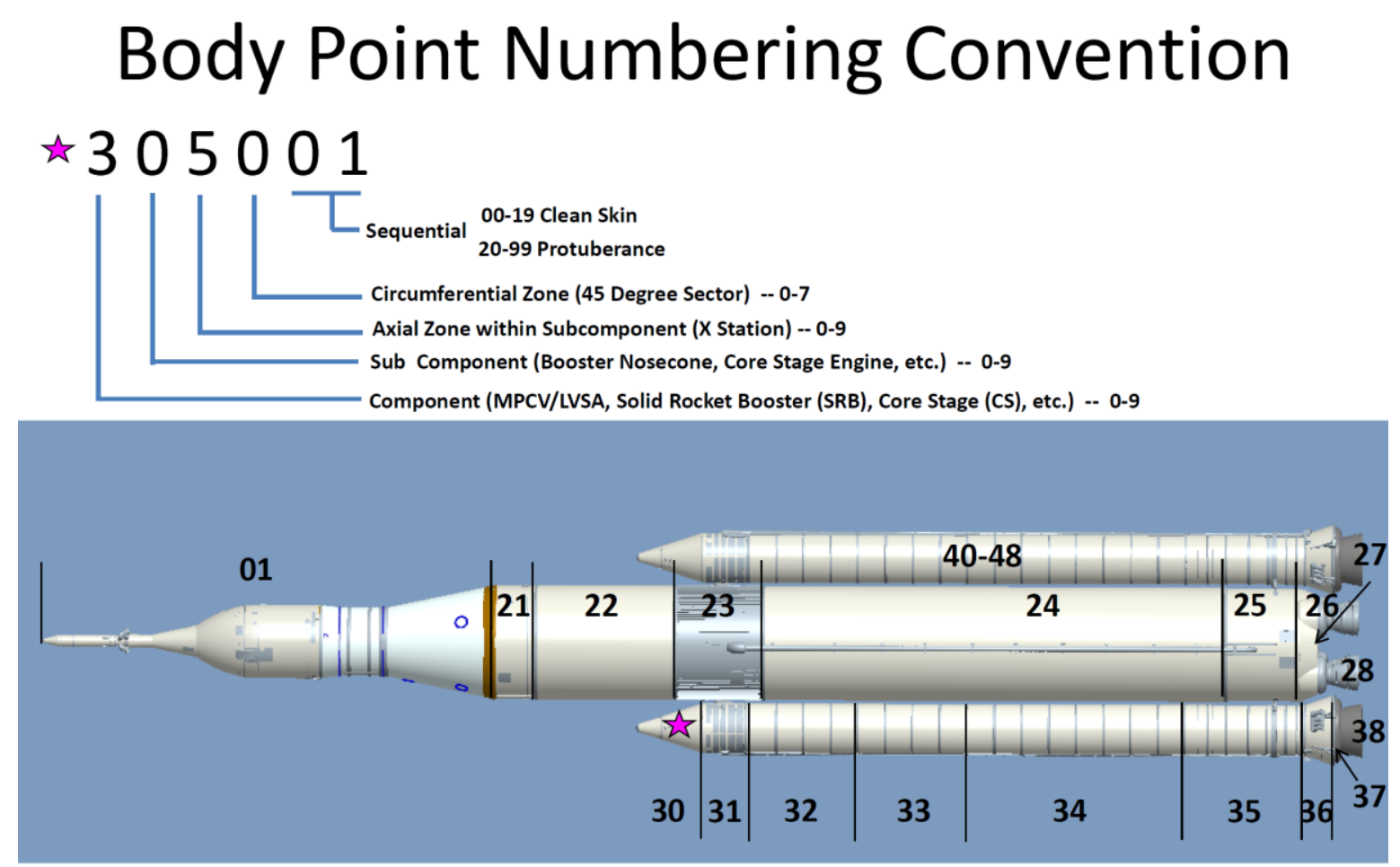

- Environments are generated at a large number of particular locations (body points) on the vehicle

- Three key inputs needed to develop aerothermal environments

- Vehicle geometry

- Engine/motor operating parameters

- Trajectories

- Current environments are statistical (99.7\% highest at each location) 

Processes and Codes

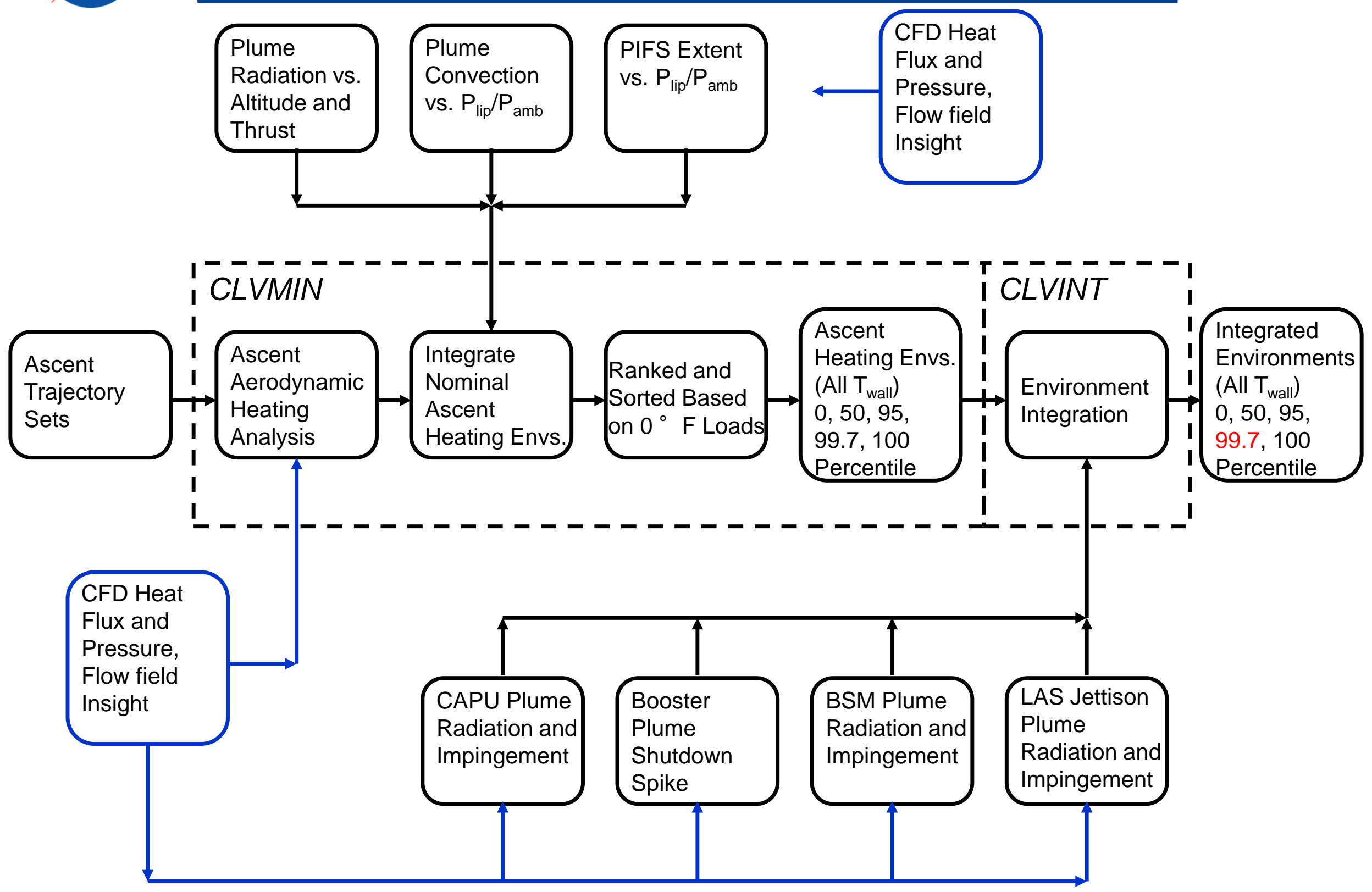




\section{SLS External Thermal Environment Prediction Aerodynamic Heating}

\section{Status}

- CLVMIN is an enhanced version of the MINIVER code

- Improved local condition determination

- Modified to generate statistical environments from trajectory sets

1. Flow field: Free stream trajectory conditions (P, T, Mach, etc.) are processed through appropriate shock(s) using compressible flow equations

2. Flow regime: Determine if continuum / transitional / rarefied / free molecular based on Mach, Reynolds \#

3. Boundary layer: If continuum flow, determine if turbulent or laminar boundary layer conditions based on Mach, Reynolds \#

4. Heating Model: Apply depending on geometry, examples: spherical - 4a (i.e. Fay \& Riddell), flat plate - 4b (Spalding-Chi w/ Mangler transformation)

5. Protuberance Factor: If needed, apply empirical or analytical amplification factor $\left(h_{i} / h_{u}\right)$

*Significant use of empirical amplification factors for core stage and booster geometry with extensive flight/wind tunnel testing history

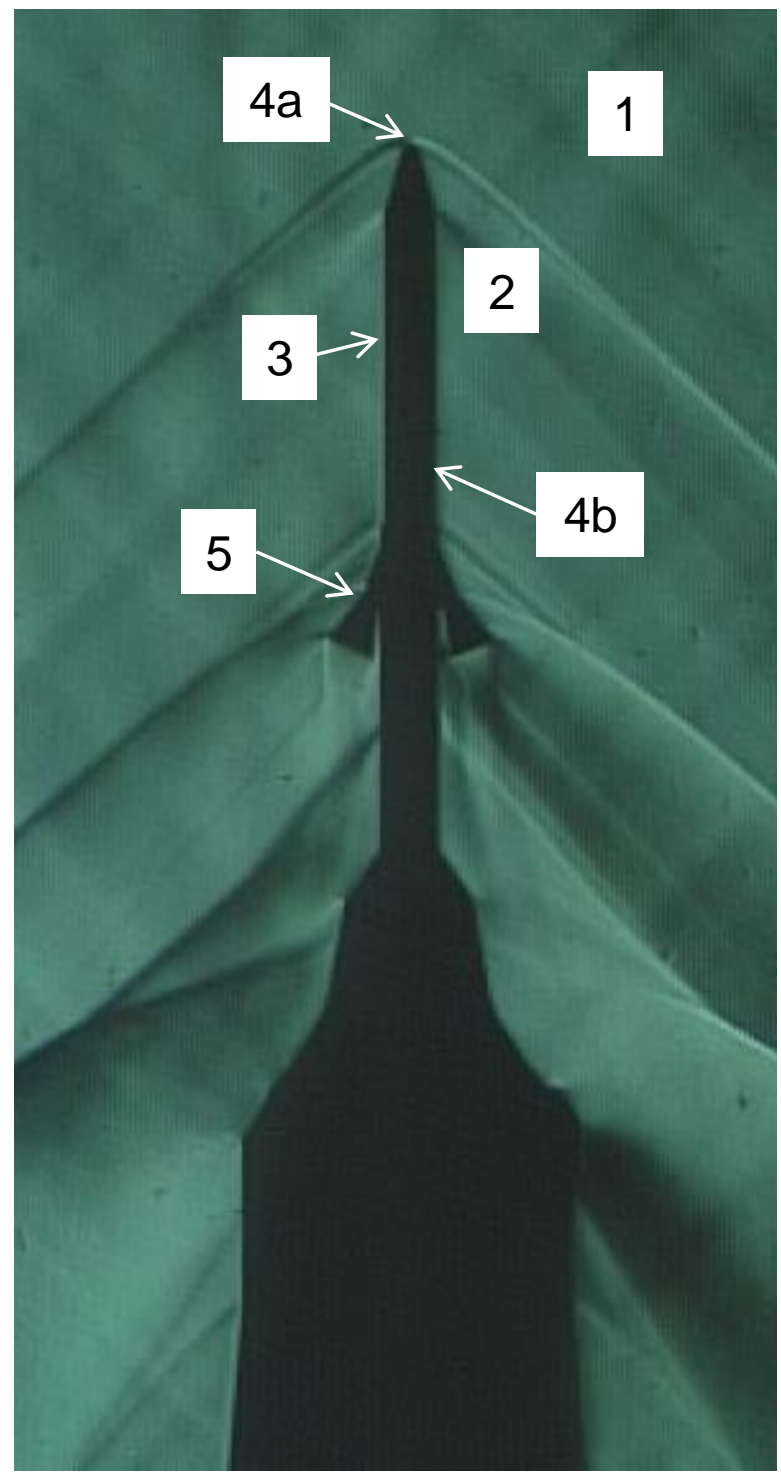




\section{- Status}

- Eight CFD cases completed

- SLS-10005 OML

- TD3 6-DOF trajectory sets

- Altitudes from 50 to $160 \mathrm{kft}$

- Mach numbers from 2.0 to 4.5

- Loci/CHEM CFD code

- 360M Cells (unstructured)

- RANS turbulence modeling

- $h_{\mathrm{i}} / h_{\mathrm{u}}$ factors developed from solutions using protuberance heating and local "clean-skin" heating

- Future Work

- Compare predictions with ATA-003 aerodynamic heating test

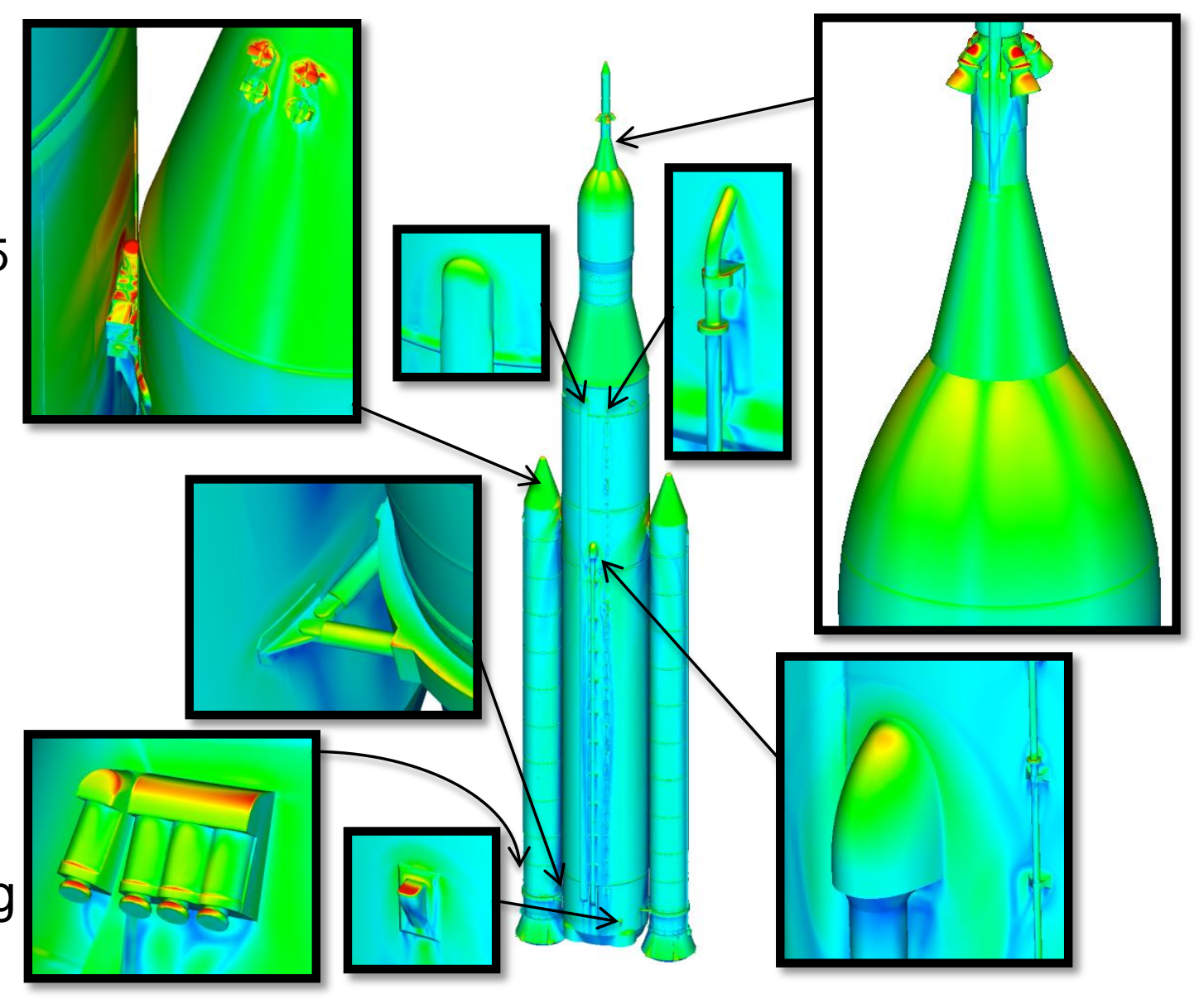

- Re-run using updated VAC1 vehicle geometry 


\section{SLS External Thermal Environment Prediction Small Protuberance Methodology}

\section{- Status}

- Recently-completed SLS small protuberance methodology is based on results from several hundred Loci/CHEM 2-D RANS CFD cases

- Intended to provide simple estimate of enhanced heating for small ( $<0.5$ inch) protuberances significantly smaller than the local boundary layer thickness

- Results for relatively smooth protuberances show good agreement with the semi-empirical formula reported by Jaeck, 1966 in flow scenarios the formula was intended for, but important differences in scenarios it was not

\section{- Ongoing Work}

- Evaluate wider range of turbulence models based on separate Loci/CHEM RANS flow separation study

- Compare with small-protuberance heating data from 103-AH and ATA-001 tests
Circular arc protuberance

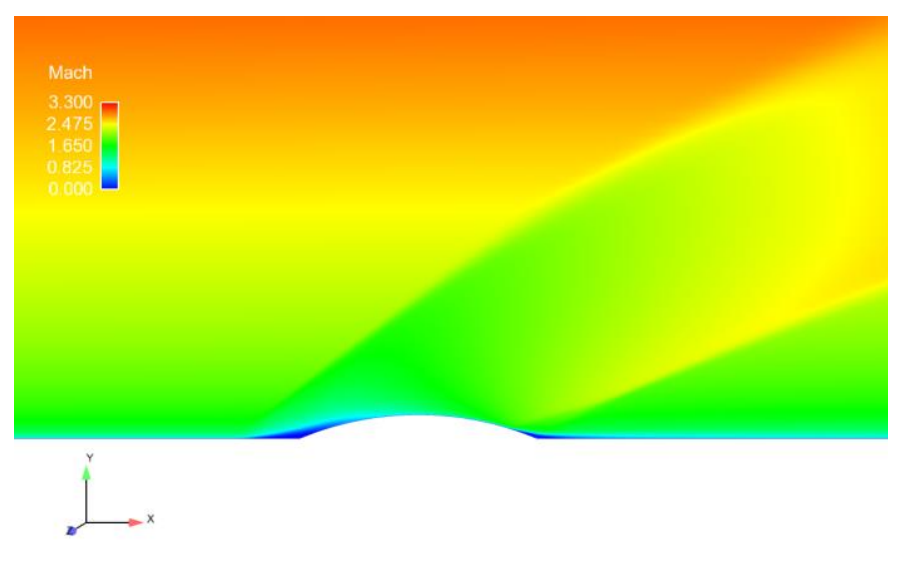

Step protuberance

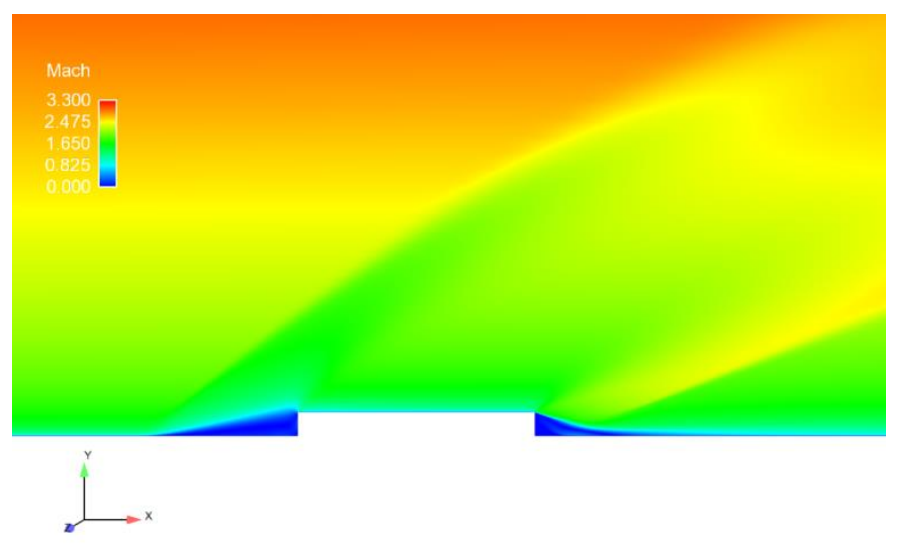




\section{SLS External Thermal Environment Prediction Plume Radiation Heating}

\section{$\checkmark$ Status}

- Plume radiation heating primarily driven by $\mathrm{H}_{2} \mathrm{O}$ in RS-25 plume Mach discs and $\mathrm{Al}_{2} \mathrm{O}_{3}$ particles in booster exhaust most significant early in flight

- Dominant heat load for areas of the vehicle base which have a clear view of the Booster and RS-25 plumes

- Typically calculated using two step process - calculate plume using CEC/RAMP2/SPF, then model radiation:

- Reverse Monte-Carlo (RMC) code for multi-phase (Booster) plumes

- Gaseous Radiation (GRAD) code for gasonly (RS-25) plumes

- Radiation calculated at various altitudes for SLS ascent

- "Shutdown spike" is captured
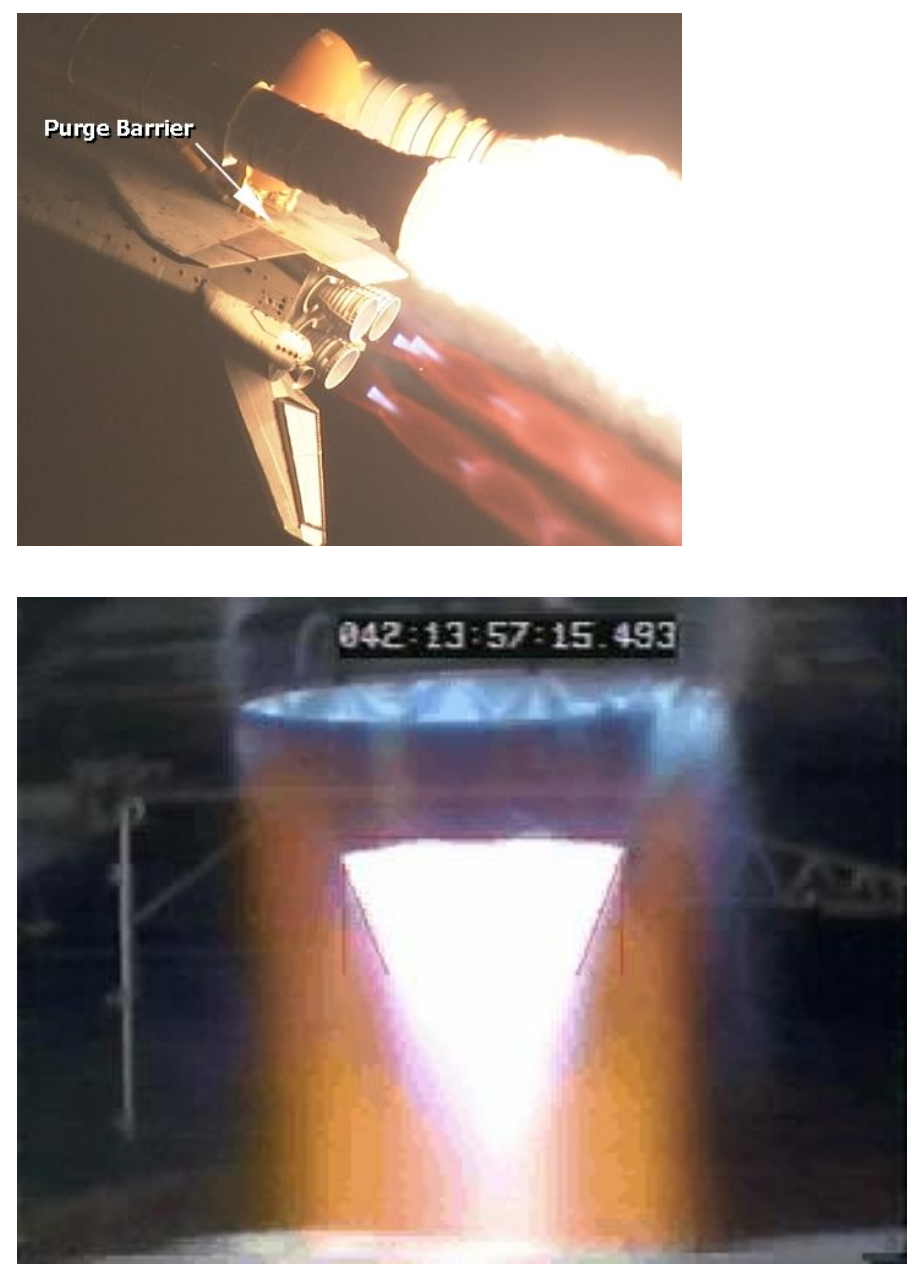


\section{SLS External Thermal Environment Prediction Base Convective Heating}

- Base convection and pressure change w/ altitude and Mach number

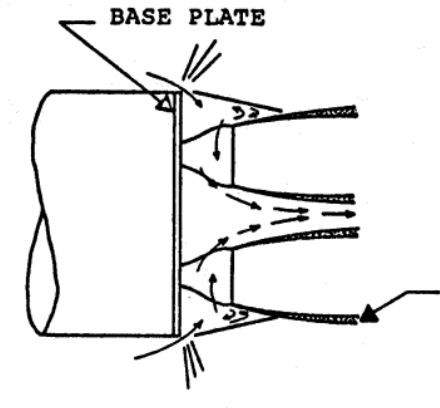

ASPIRATION FLOW (LOW ALTITUDE)

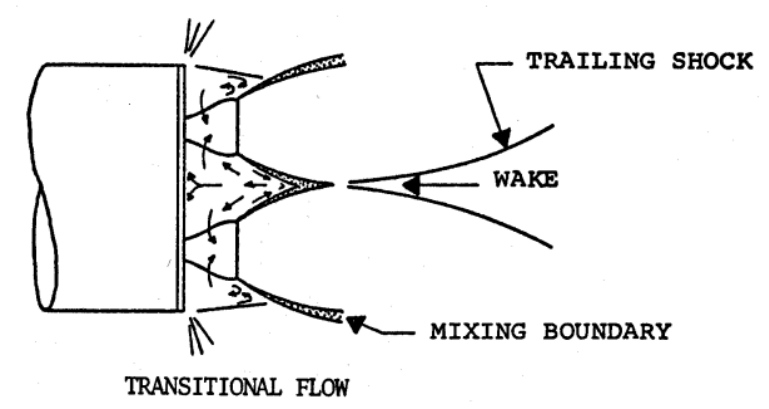

TRANSITIONAL FLOW

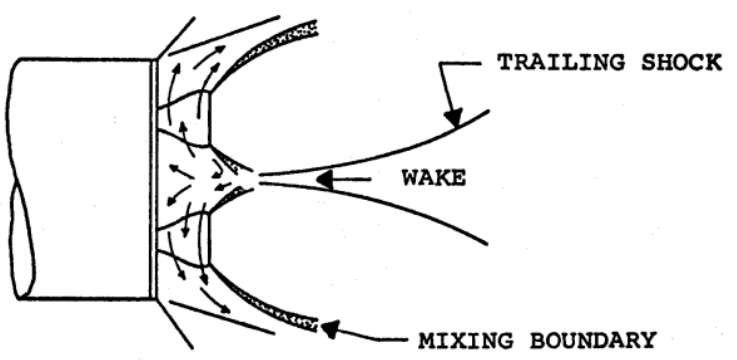

CHOKED REVERSE FLOW (HIGH ALTITUDE)
ASCENT BASE PRESSURE TRENDS

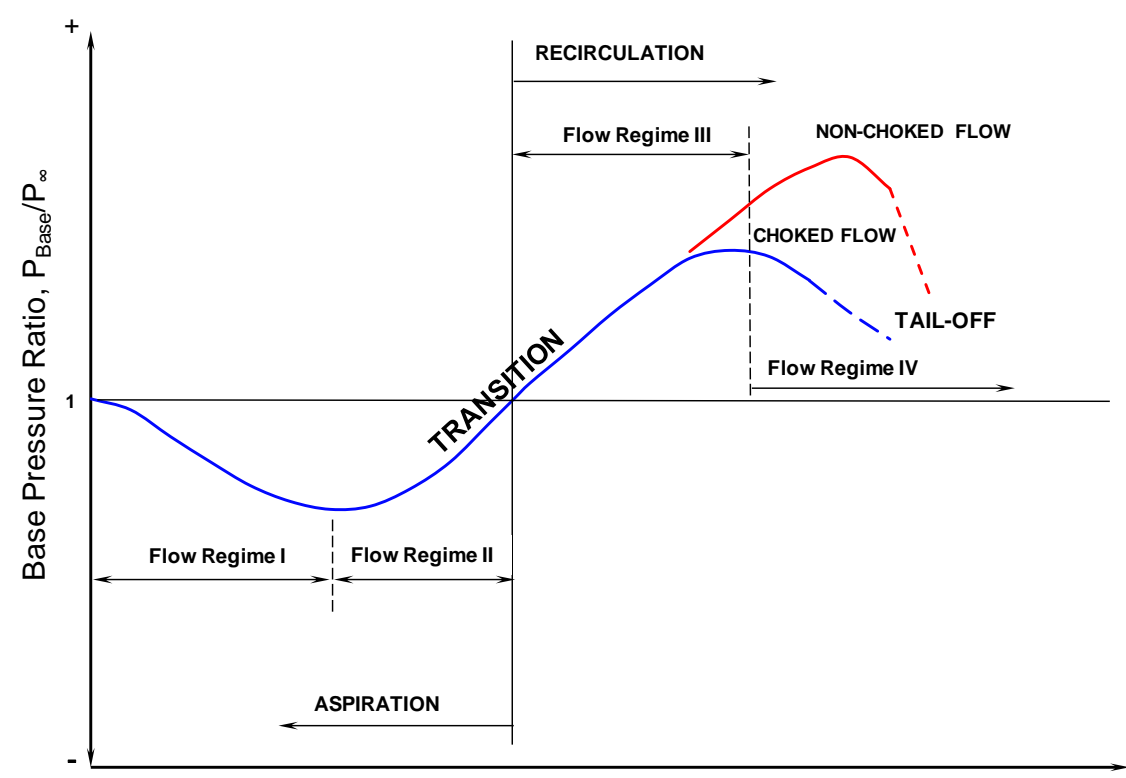

Altitude Increasing

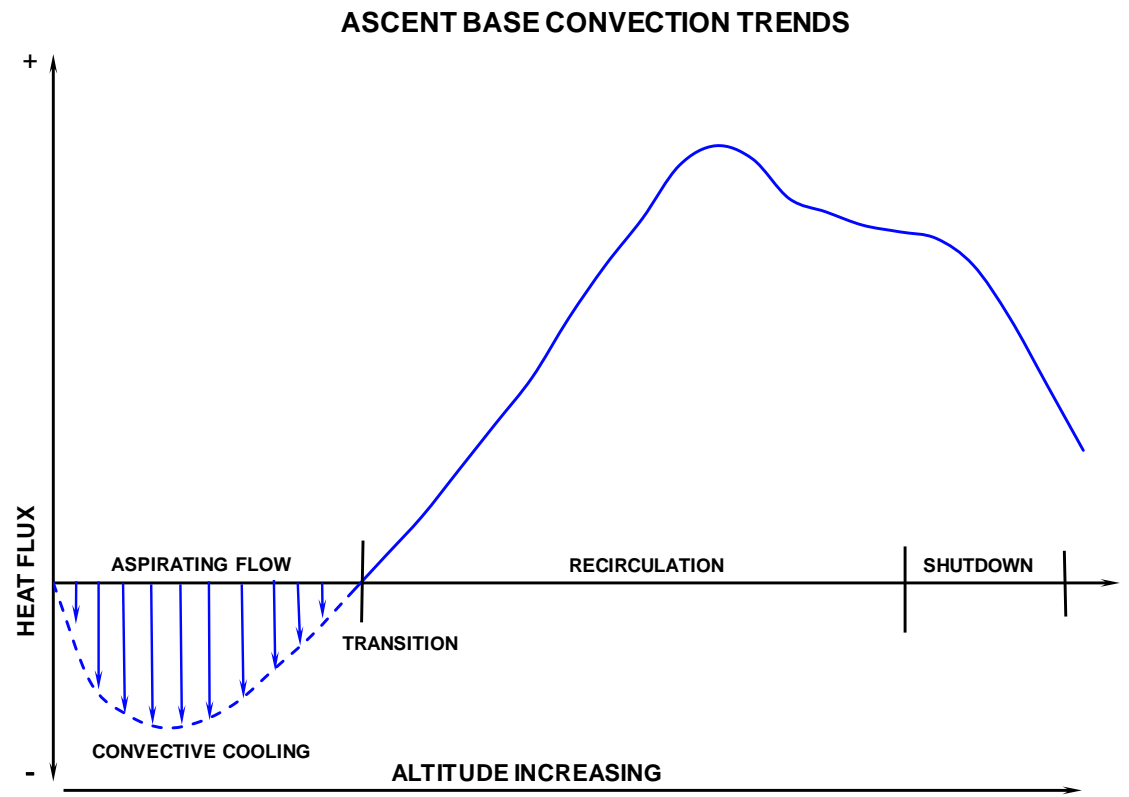




\section{SLS External Thermal Environment Prediction Base Convective Heating}

\section{- Status}

- Current methodology predicts base convective heating using semi-empirical approach $\left(\mathrm{P}_{\text {lip }} / \mathrm{P}_{\mathrm{amb}}\right.$ ratio) derived from Saturn V, Shuttle and wind tunnel data

- CFD predictions of base convective heating differ from semi-empirical method

- ATA-002 test is assessing conservatism in existing design environments and will lead to improved models

- Pathfinder developed $2 \%$ scale model propulsion system

- Main base heating test is currently underway at CUBRC

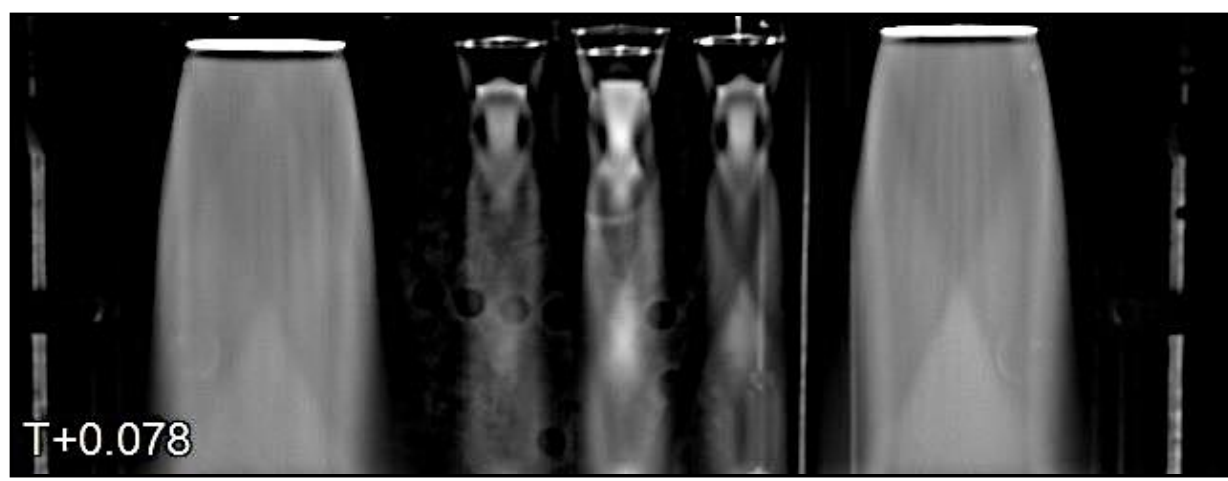

Long-wave infrared image of $2 \%$ scale propulsion system plumes firing at sea-level. Note that the $2 \%$ scale Core Stage RS-25 engine nozzles are rotated $\mathbf{4 5}$ degrees from their normal orientation.

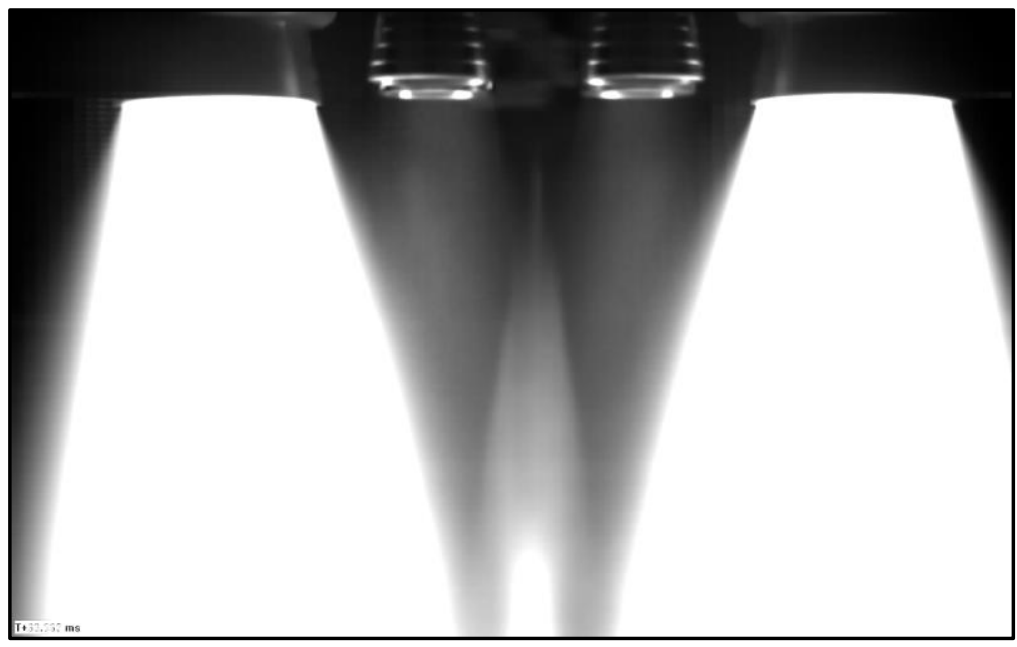

Integrated visible wavelength image of $2 \%$ scale propulsion system firing at a freestream condition consistent with $100,000 \mathrm{ft}$ altitude. 


\section{SLS External Thermal Environment Prediction Plume Induced Flow Separation (PIFS) Heating}

\section{- Status}

- Current methodology predicts PIFS heating based on Shuttle and Saturn $V$ data and $\mathrm{P}_{\text {lip }} / \mathrm{P}_{\text {amb }}$ ratio

- PIFS heating on the Core stage and Booster is applied by circumferential zones

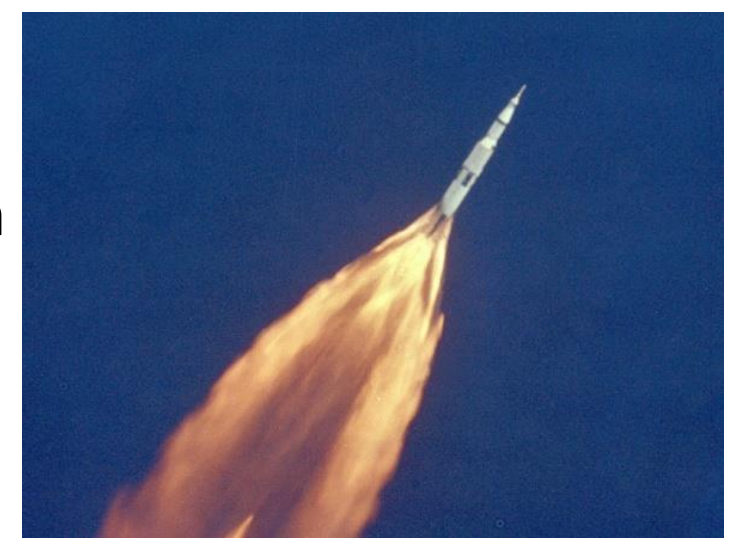

\section{- Ongoing Work}

- Three CFD cases completed for camera contamination study

- Loci/CHEM CFD solutions

- Altitudes from 94 to $147 \mathrm{kft}$

- Mach numbers from 3.5 to 4.5

- Will compare with baseline semiempirical methodology

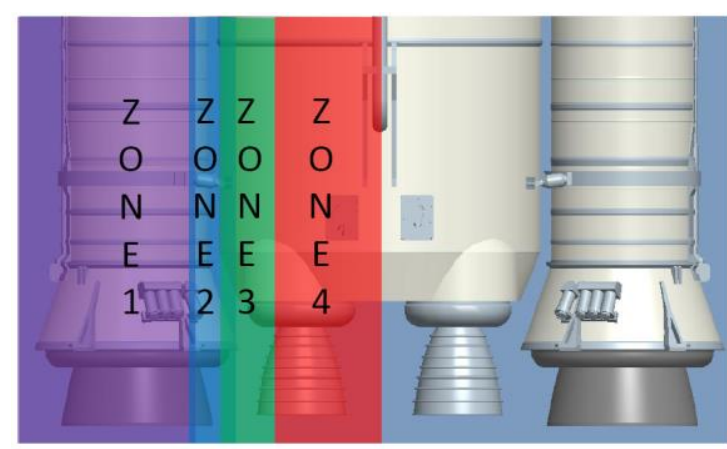

Mach
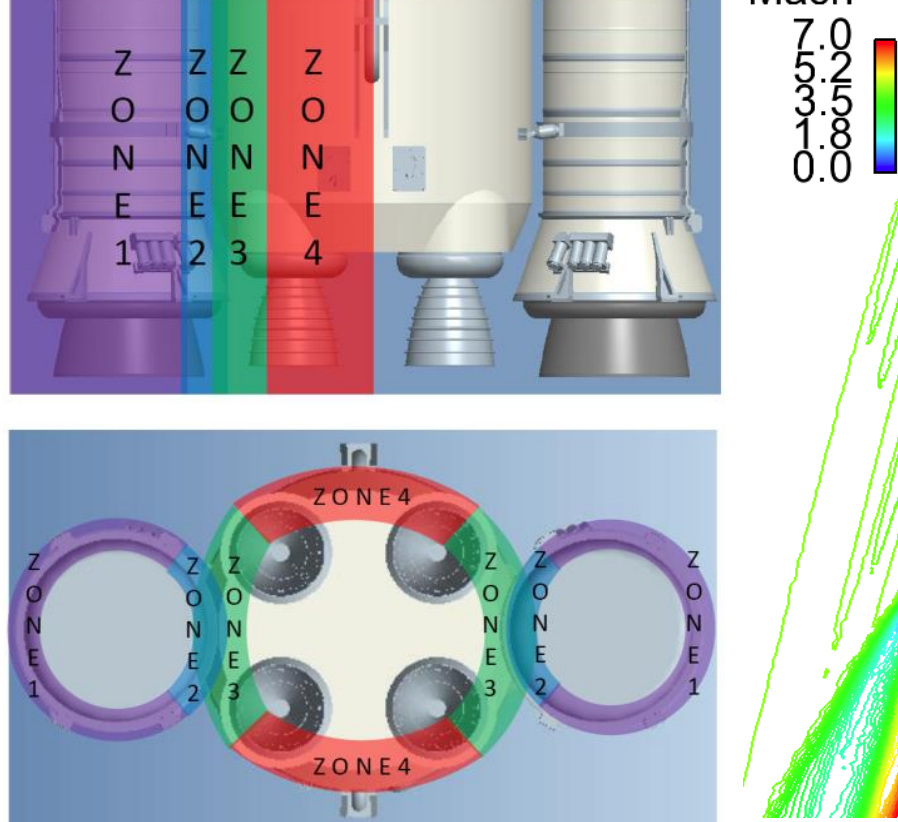


\section{$\checkmark$ Status}

- Total of four cases completed at 0.02, 0.2, 0.4, and 0.6 seconds after initiation of booster separation

- Loci/CHEM unstructured CFD code

- 120M cell grid assumes flow field symmetry

- RANS turbulence modeling and frozen chemistry

- Plume gases modeled as a single equivalent gas

- High confidence in direct plume impingement heating prediction from CFD, based on Constellation-era tests and Ares I-X flight data

- Updates to these BSM simulations are currently underway, as well as comparisons to new Shuttle BSM CFD models

- Recently completed updated CFD simulations for the Orion MPCV Launch Abort System (LAS) Jettison Motor (JM)

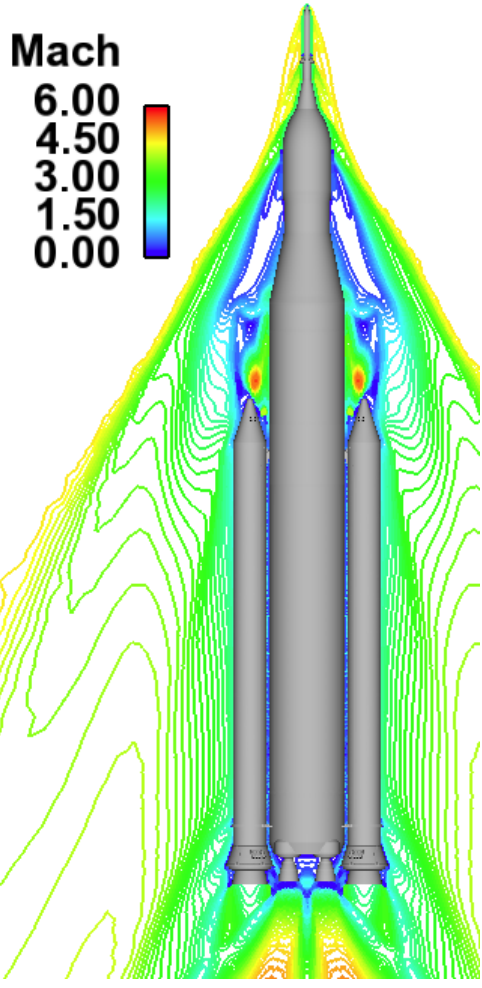
plume impingement environments

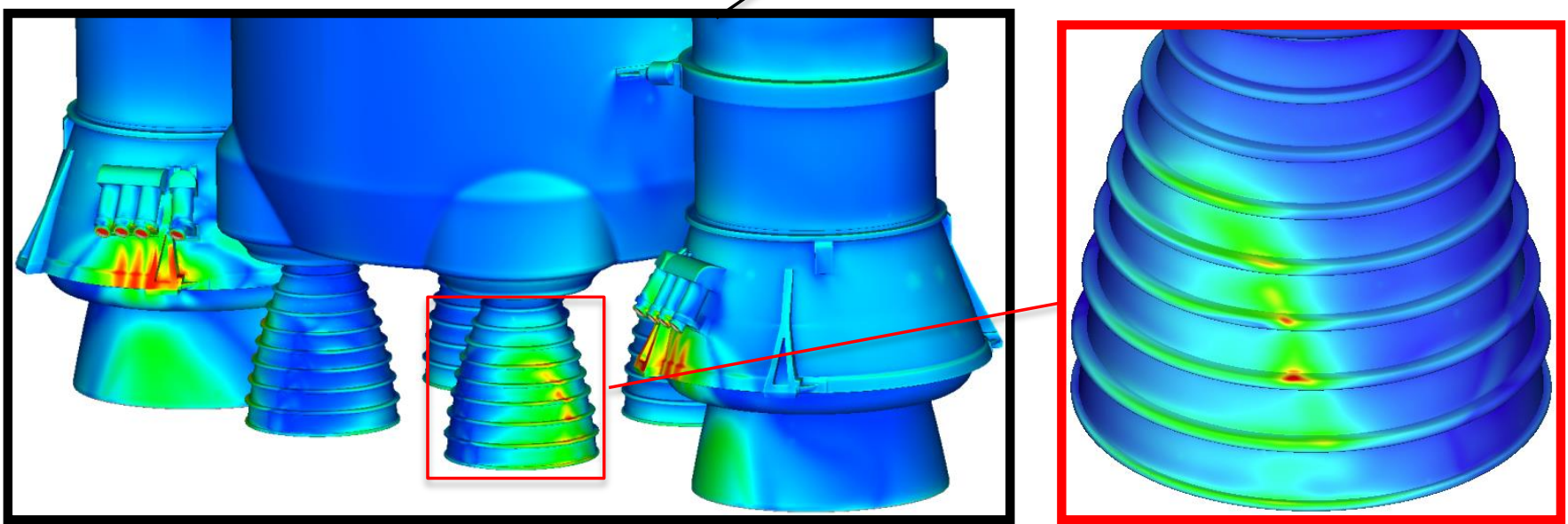




\section{SLS External Thermal Environment Prediction Core Auxiliary Power Unit (CAPU) Plume Heating}

\section{- Status}

- CAPU system drives hydraulic fluid used for RS-25 gimballing and throttling

- Powered in flight by $\mathrm{H}_{2}$ gas tapped off from main propulsion system

- Loci/CHEM CFD solutions

$-\sim 200 \mathrm{M}$ cell grid

- 6 species $\left(\mathrm{O}_{2}, \mathrm{~N}_{2}, \mathrm{H}_{2}, \mathrm{H}_{2} \mathrm{O}+2\right.$ equivalent plume gas species)

- Fast $2 \mathrm{H}_{2}+\mathrm{O}_{2} \rightarrow 2 \mathrm{H}_{2} \mathrm{O}$ chemistry assumed

- Solutions throughout Boost Stage flight completed

- Convective heating environments developed from analysis and simplification of these solutions

- Updated CFD simulations with revised CAPU duty cycle inputs are currently underway

- Radiative heating initially developed from simplified plume models, but full consistency with CFD models is planned
Iso-surfaces of $10 \% \mathrm{H}_{2} \mathrm{O}$ Mass Fraction RS-25 and Booster Plume Exhaust Not Shown for Clarity

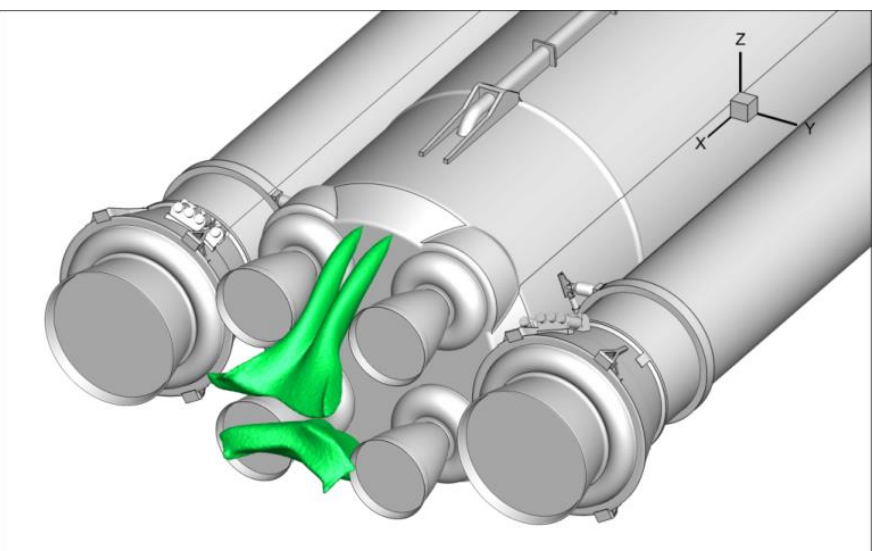

Mach 0.1, $600 \mathrm{ft}$

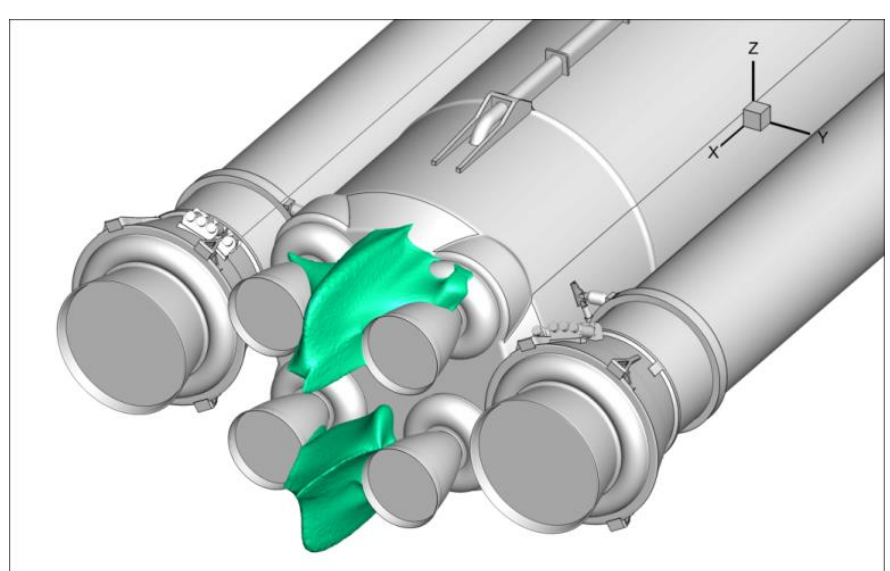

Mach 2, 51,000 ft 


\section{Summary and Status}

- The third DAC cycle for SLS is complete and the program is moving toward its Critical Design Review

- External Thermal environments for the vehicle are integrated from several different sources of heating:

- Aerodynamic heating

- Plume radiation heating

- Plume base convection/recirculation heating

- Plume induced flow separation heating

- Plume impingement heating

- CAPU plume/flame heating

- Moving forward, many of these models will be further refined with additional CFD simulations and wind tunnel testing 